\title{
Effectiveness of structured teaching programme on knowledge regarding evidence based practice among undergraduate (B.Sc) nursing students
}

\author{
Thoudam Kheroda Devi', Vijaya Kumar S $^{2, *}$ \\ ${ }^{1} \mathrm{PhD}$ Scholar, ${ }^{2}$ Professor, Dept. of Pharmacy and Pharmacology, ${ }^{1}$ Shri Jagdishprasad Jhabarmal Tibrewala University, Jhunjunu,
} Rajasthan, ${ }^{2}$ Sree Siddaganga College of Pharmacy, Tumakuru, Karnataka, India

*Corresponding Author:

Email: vijitumkur@ rediffmail.com

\begin{abstract}
Evidence based nursing mainly focus on providing the best nursing care according to personnel clinical expertise and that should be in combination with the current available research topic and making quality decision. Practice based on evidence requires the incorporation of experienced staffs, involvement of research utilization into the clinical decision in order to guide the nursing care for patient welfare. ${ }^{1}$ The ultimate aim and goal of the study was to impart the information awareness of the final year B.Sc nursing students regarding the evidence based practice. The pre experimental research design was used to carry out the study in selected nursing colleges at Bangalore among the 400 final year B.Sc nursing students and purposive sampling technique was used for the selection of students. The study results reported that there was vast disparity between pre test and post test knowledge score amongst the final year nursing students after the implementation of teaching programme and nursing students acquired the adequate information on evidence based practice after attending the teaching programme.
\end{abstract}

Keywords: EBP, EBN, STP, Information awareness, Final year nursing students, Nursing colleges.

\section{Introduction}

Development of practice based on scientific evidence and its utilization is well known in the medical sector. It is the professional responsibilities for the nurses to practice the EBP in order to strengthen the quality of nursing with the adequate knowledge and skills as nurses are the accountable to the society for the service they deliver to the people and to utilize the best current evidence by doing research and to provide the meaningful treatment and best outcome for the patient. Nursing practice based on rational will enhance the information awareness and capability of the young nurses, increase the confidence, performance and adaptability among the nurses, create the creative thought and involved in the decision making process with the clinician regarding patient care. ${ }^{2}$ Evidence based practice would also leads to job satisfaction and job retention among the nurses in the health care as well as cost effectiveness as evidence based practice would manage the available resources effectively and efficiently. ${ }^{3}$

\section{Objectives of the study}

1. To determine the pre test information awareness on evidence based practice in nursing amongst $4^{\text {th }}$ year B.Sc nursing students.

2. To administer the structured teaching programme on evidence based practice amongst $4^{\text {th }}$ year B.Sc nursing students.

3. To evaluate the effectiveness of structured teaching programme on knowledge regarding evidence based practice in nursing among $4^{\text {th }}$ year B.Sc nursing students.
4. To determine the relevance between information awareness and bio characteristic inputs on evidence based practice in nursing.

\section{Hypothesis}

$\mathbf{H}_{1}$ : There will be a vast disparity between pre test and post test knowledge score regarding evidence based practice and its importance to the nursing practice amongst the degree students of $4^{\text {th }}$ year in nursing.

$\mathbf{H}_{2}$ : There will be considerable amount of relevance between the knowledge scores of the students with their bio characteristic inputs.

\section{Material and Methods}

The study was pre-experimental in nature and adopted the one group pre test post test research design. Sample size was 400 final year B. Sc nursing students from the selected nursing colleges at Bangalore. Purposive sampling technique was used for the collection of information from the participants. ${ }^{4}$ The information from the participants was collected by using structured questionnaire. The complete tool consists of student's base line data in related to the study and well prepared structure knowledge multiple choice questionnaire tool based on evidence based practice, evidence based nursing and general aspect of evidence based practice to determine the information awareness of the degree students in the field of nursing. ${ }^{5}$ The maximum score given was 50 and the minimum score was considered as 0 . Based on the scoring the percentage of knowledge was calculated by using formula. The description of developed tool used for the data collection procedure to evaluate the effectiveness of structured teaching programme on knowledge regarding evidence based 
practice and its importance in nursing among the degree students. Collected data was analyzed for drawing the effective results and conclusion. ${ }^{6}$

The structured teaching programme was developed keeping in mind the objectives, literature review and the opinion of experts. Further literacy level of the sample, simplicity of the language, method of teaching relevance and the attention span of students were also considered. The STP was drafted in English. It was given to the experts and these were $100 \%$ agreement regarding content by all experts, except minor modifications. The STP was prepared based on the title of the topic and objective selected for the study. The components included in the STP are introduction and basic concept of evidence based practice, evidence based nursing, steps of EBP, model used to implement the EBP, problems and obstacle to implement the EBP, opportunities and challenges for EBP and implication for the nurses. ${ }^{7}$ STP was conducted in the morning session and Student's feedbacks were obtained by asking the questions and conducting the post test to evaluate the effectiveness of STP. ${ }^{8}$

\section{Results}

The finding of the study reported that the B. Sc nursing students according to level of knowledge before and after administering STP. In the present pre-test, a majority 357(89.3\%) had insufficient knowledge, average information awareness was found amongst the $43(10.8 \%)$ nursing student and none of them had sufficient knowledge on evidence based practice in nursing. Whereas after the intervention of STP, all students $400(100 \%)$ had adequate knowledge on EBP in nursing and none of them remain in without adequate information awareness on utilization of practice based evidence in nursing practice. It evidences the improvement in knowledge after the administration of teaching programme on EBP and STP was found effective.

Table 1: Mean, Standard Deviation and mean percentage of knowledge regarding evidence based practice in nursing among $B$. Sc nursing students. $n=400$

\begin{tabular}{|c|c|c|c|c|c|c|c|c|c|c|}
\hline \multirow{2}{*}{$\begin{array}{c}\text { S. } \\
\text { No }\end{array}$} & \multirow{2}{*}{$\begin{array}{l}\text { Aspects of } \\
\text { knowledge }\end{array}$} & \multirow{2}{*}{$\begin{array}{l}\text { Max } \\
\text { score }\end{array}$} & \multicolumn{4}{|c|}{ Pre-test } & \multicolumn{4}{|c|}{ Post-test } \\
\hline & & & Range & Mean & SD & $\begin{array}{c}\text { Mean } \\
\%\end{array}$ & Range & Mean & SD & $\begin{array}{c}\text { Mean } \\
\%\end{array}$ \\
\hline 1 & $\begin{array}{l}\text { Multiple choice } \\
\text { questionnaires on } \\
\text { EBP }\end{array}$ & 32 & $10-21$ & 11.17 & 2.58 & 34.9 & $26-32$ & 27.56 & 0.82 & 86.1 \\
\hline 2 & $\begin{array}{l}\text { Multiple choice } \\
\text { questionnaires on } \\
\text { EBN }\end{array}$ & 8 & $2-6$ & 2.79 & 0.58 & 34.8 & $5-8$ & 7.15 & 1.18 & 89.3 \\
\hline 3 & $\begin{array}{l}\text { Multiple choice } \\
\text { type questions on } \\
\text { general aspect of } \\
\text { EBP }\end{array}$ & 10 & $1-6$ & 2.86 & 1.12 & 28.6 & $8-10$ & 9.36 & 0.68 & 93.6 \\
\hline 4 & Over all & 50 & $14-29$ & 16.83 & 3.44 & 33.6 & $40-48$ & 44.07 & 1.98 & 88.1 \\
\hline
\end{tabular}

Table 2: Effectiveness of STP by comparing the pre and post test knowledge regarding EBP. n=400

\begin{tabular}{|c|c|c|c|c|c|c|c|}
\hline \multirow{2}{*}{$\begin{array}{l}\text { S. } \\
\text { No }\end{array}$} & \multirow{2}{*}{ Aspect of knowledge } & \multirow{2}{*}{$\begin{array}{c}\text { Max } \\
\text { score }\end{array}$} & \multicolumn{3}{|c|}{ Enhancement } & \multirow{2}{*}{$\begin{array}{c}\text { t-test } \\
\text { value }\end{array}$} & \multirow{2}{*}{ P-value } \\
\hline & & & Mean & SD & Mean\% & & \\
\hline 1. & $\begin{array}{l}\text { Knowledge } \\
\text { questionnaires on } \\
\text { evidence based practice }\end{array}$ & 32 & 16.39 & 2.71 & 51.2 & 120.61 & $\mathrm{p}<0.05$ \\
\hline 2. & $\begin{array}{l}\text { Knowledge } \\
\text { questionnaire on } \\
\text { evidence based nursing }\end{array}$ & 8 & 4.33 & 1.30 & 54.1 & 66.73 & $\mathrm{p}<0.05$ \\
\hline 3. & $\begin{array}{l}\text { Knowledge } \\
\text { questionnaire on general } \\
\text { aspect of evidence based } \\
\text { practice }\end{array}$ & 10 & 6.49 & 1.32 & 64.9 & 97.79 & $\mathrm{p}<0.05$ \\
\hline 4. & Over all & 50 & 27.24 & 4.04 & 54.4 & 134.61 & $\mathrm{p}<0.05$ \\
\hline
\end{tabular}

*Significant at $\mathrm{p}<0.05$ level, $399 \mathrm{df}$. 


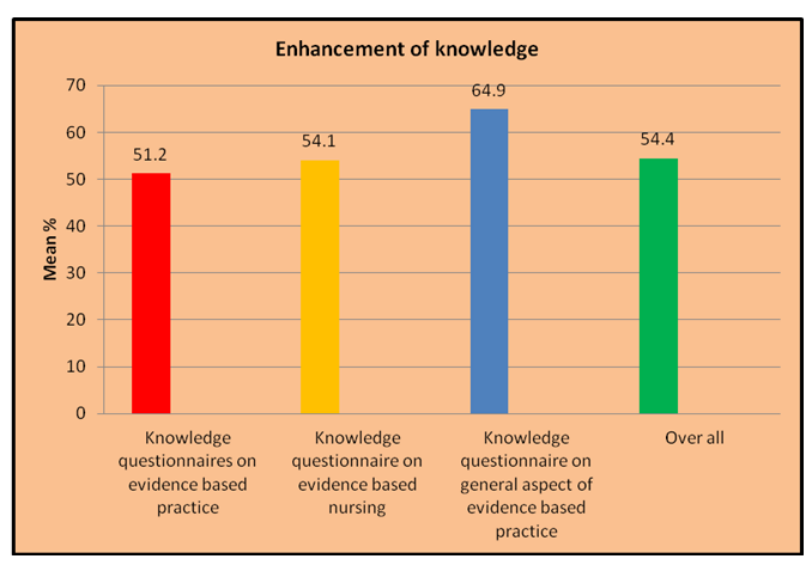

Fig. 1: Paired t-test analysis for effectiveness of STP

The paired $t$ test analysis was used in order to find out the effectiveness of programme through pre test and post test results. The analysis shows that there was a mean difference in all the aspects of knowledge regarding EBP in nursing such as the enhancement of mean value was 27.24 , standard deviation value was 4.04 and means percentage value was $54.4 \%$. This was percent of enhancement of knowledge. The study was found to be Significant at $p<0.05$ level, $399 \mathrm{df}$ with the $t$ test value of 134.61. The analysis described that there was a vast disparity in the scores obtained during the pre test and post test. The knowledge scores after attending the teaching session was found to be higher than the scores without attending the teaching programme on EBP. Hence, STP was found effective for imparting the information awareness on EBP amongst nursing students.

\section{Discussion}

This study was conducted amongst the final year B.Sc nursing students at the sort listed eligible nursing colleges at Bangalore to identify their information awareness and to provide a well structured teaching programme amongst them. The activities include reaching out the concerned institutions, seeking permission from the appellate authority. Post seeking permission, a preferable date and time was selected with creation of lesson plan and audio visual aids. Seeking volunteers from the students of the institution and building up their confidence level about the programme and administering the teaching plan / topic inside the conference room. With proper planning and execution, the programmed proved to be a successful event and received wide appreciation from the students and teaching faculty.

The results showed that all the participants had positive attitude towards the EBP programme and attended the teaching programme. The results were derived using the Paired t- test analysis and shows a positive result. All the 400 participants (100\%) achieved adequate information on evidence based practice and teaching programme was found to be useful to impart the enough information amongst the nursing students to prepare them to utilize the EBP in their clinical practice.

\section{Conclusion}

Evidence based practice helps the nursing personnel to improve their information awareness and preparation to promote the standard of nursing profession. Nurses are the one who is playing a main important role in the health care sectors by providing the good and supportive care to the patients and satisfying the need of the patients. ${ }^{9}$ By the same time patients have the complete right to know the scientific reason for each and every care they are receiving daily in the hospital. Opportunities should be provided to the nurses to focus on their professional development like evidence synthesis and utilization of research projects in their curriculum. Therefore an effective teaching and training on evidence based nursing practice programme among the nursing students is quite essential. ${ }^{10}$

\section{References}

1. Aronson BS, Enhancing evidence bases for interventions in a baccalaureate program. Nurs Educ Perspect. 2007;28(5):257-62.

2. Barnsteiner J and Prevost S (2002), How to implement evidence based practice. Reflect Nurs Leadersh 28(2):1821.

3. Catriona M Doody and Owen Doody (2011), Introducing evidence into nursing practice. Br J Nursing 20(11):661663.

4. Polit D.F and B.P Hungler, "Textbook of nursing research principles and methods", Lippincott publications:57.

5. Harrow D, Foster J (2001), Evidence and leadership, The tools for change. Contemp Nurse 2001;11(1):9-17.

6. Jacobs JA, Jones E (2012), Tools for implementing an evidence-based approach in public health practice. Prev Chronic Dis 2012;9: E116. Epub 2012 Jun 21.

7. Kim SC, Brown CE (2009), Evidence-based practicefocused interactive teaching strategy: a controlled study. $J$ Adv Nurs 2009;65(6):1218-27.

8. María Ruzafa-Martínez, Effectiveness of an evidencebased practice (EBP) course on the EBP competence of undergraduate nursing students. 2016;38:82-7.

9. Moch SD, Cronje RJ (2010), Undergraduate nursing evidence-based practice education. J Prof Nurs 2010;26(1):5-13.

10. Emanuel V et al (2011) Developing evidence-based practice among students. Nursing Times 107:49/50, 2123. 